necessarily to detract from the achievement of such people. I merely wish to make the point that, in a culture that finds some criterion of 'authenticity' in mental torment, proving an association between genius and insanity becomes a rather tautologous exercise.

Incidentally, anyone who doubts the social aspects of 'genius' might like to consider the extraordinary case of women. Can the apparent paucity of female geniuses in our culture really be due to innate biological differences?

I do not think that we shall arrive at any useful understanding of this conundrum by the drawing up of rival 1st XIs of Those Who Were vs. Those Who Weren't. While it may be possible to make genetic and psychological studies of certain well-defined aspects of creativity, genius is a sociological animal and any account of it will have to be in its own terms.

Guy's Hospital Medical School

J. E. B. LINDESAY

London SEI

\section{Dear Sir}

The relationship of 'insanity and genius' is a controversial issue. That it is also a very fascinating one is demonstrated by the number of your correspondents (Bulletin, March $1983,7,55$; July 1983, 129-30; October 1983,188 ). The advertisement having originally instigated the correspondence seems to me an example of poor taste rather than a contribution to the basic question and not worth further discussion. I did appreciate, though, one correspondent's (October 1983) apt summary of our knowledge, to which I want to add a few comments.

An outstanding example of 'allusive' (or innovative) thinking is the poet Friedrich Hölderlin. He had written some of the most beautiful and innovative poems of the German language before he suffered a mental breakdown at the age of thirty-one. Thereafter, until his death $\mathbf{4 2}$ years later, he lived in a condition which psychopathologists used to diagnose as chronic schizophrenia, whereas some more recent biographers, mostly non-psychiatrists, feel certain Hölderlin withdrew purposely from a world which did not conform to his ideals. Whatever the evaluation of his condi- tion, a life span of 42 years spent distant to the world and limited in scope cannot be called sane, and nobody with any feeling for poetry could deny the writer of such unique poems the epithet of genius.

I further want to refer to Hans Prinzhorn's famous book Die Bildnerei der Geisteskranken. As painters (or other artists) gifted with genius can become insane, so sometimes the insane can create ingenious works of art. In a recent publication (Luckless Heads (1982) edited by Ulli Beier, Bremen: Edition $\mathrm{CON}$ ), pictures of high artistic quality are presented, drawn and painted more than 30 years ago by Nigerian mental patients, confined to a 'lunatic asylum', most of them never having had previous contact with paint, pencil or paper.

Could mental disease, one is tempted to speculate, sometimes release productive abilities? However, in my opinion it is no answer to call a myth what one cannot (yet?) scientifically explain, be it insanity, genius, or an apparent association between the two.

Segeberger Landstr. 17

D-2300 Kiel 14, W. Germany

Psychiatry by remote control?

\section{DeAr Sir}

As a residential child care officer, untrained in the workings of psychiatry, I have recently been intrigued by the behaviour of a consultant from one of London's eminent teaching hospitals, to whom we had referred one of the children in our care, a 16 year old girl.

Over the course of several months he made three visits to our establishment, always accompanied by a number of junior colleagues, and at the end of this time he arrived at both a diagnosis and a recommendation for treatment.

All very proper, of course, except that at no time did he actually see the patient herself, nor take any notice of her expressed wish to see him. I know that we are embarking upon a new age of technology, but does this necessarily entail psychiatry by remote control?

SYLVYA ROSE

15 Camberwell Church Street

London SES

\title{
Reception for Dr J. L. Crammer
}

A reception in honour of the retiring editor, DR J. L. Crammer, and Mrs Crammer, was held at the College on Wednesday 17 November 1983. Guests included the President and Council; College Officers; Members and Fellows associated with the Journal; the printers, Mr D. Pitt and Mr R. Milbery; the advertising manager, Mr P. Mell; and the editors of the Lancet and the British Medical Journal.
Dr Crammer writes: 'We would like to thank all those who combined to give us a beautiful Chinese silk carpet decorated with clouds (for joy) and cranes (for longevity) as well as some wine and a basket of azaleas. The carpet is an exciting permanent symbol of the kindness I have received from many people in five years as an assistant editor and over six in the editorial chair!' 